\title{
Developments in the production of platelets from stem cells (Review)
}

\author{
JIE YANG $^{1}$, JIANFENG LUAN ${ }^{2}$, YANFEI SHEN ${ }^{3}$ and BAOAN CHEN ${ }^{1}$ \\ ${ }^{1}$ Department of Hematology and Oncology, School of Medicine, Zhongda Hospital, \\ Southeast University, Nanjing, Jiangsu 210009; ${ }^{2}$ Jinling Hospital Department of Blood Transfusion, \\ School of Medicine, Nanjing University, Nanjing, Jiangsu 210002; ${ }^{3}$ Medical School, School of Chemistry \\ and Chemical Engineering, Southeast University, Nanjing, Jiangsu 210009, P.R. China
}

Received July 22, 2020; Accepted October 13, 2020

DOI: $10.3892 / \mathrm{mmr} .2020 .11645$

\begin{abstract}
Platelets are small pieces of cytoplasm that have become detached from the cytoplasm of mature megakaryocytes (MKs) in the bone marrow. Platelets modulate vascular system integrity and serve important role, particularly in hemostasis. With the rapid development of clinical medicine, the demand for platelet transfusion as a life-saving intervention increases continuously. Stem cell technology appears to be highly promising for transfusion medicine, and the generation of platelets from stem cells would be of great value in the clinical setting. Furthermore, several studies have been undertaken to investigate the potential of producing platelets from stem cells. Initial success has been achieved in terms of the yields and function of platelets generated from stem cells. However, the requirements of clinical practice remain unmet. The aim of the present review was to focus on several sources of stem cells and factors that induce MK differentiation. Updated information on current research into the genetic regulation of megakaryocytopoiesis and platelet generation was summarized. Additionally, advanced strategies of platelet generation were reviewed and the progress made in this field was discussed.
\end{abstract}

\section{Contents}

1. Introduction

2. Stem cell sources

3. Gene regulation during megakaryopoiesis

4. Promotion of platelet production

5. Conclusion

Correspondence to: Professor Baoan Chen, Department of Hematology and Oncology, School of Medicine, Zhongda Hospital, Southeast University, 87 Dingjiaqiao, Nanjing, Jiangsu 210009, P.R. China

E-mail: cba8888@hotmail.com

Key words: platelet, megakaryocyte, megakaryocytopoiesis, stem cell

\section{Introduction}

In healthy adults, the mean number of platelets in the blood is maintained at $(150-400) \times 10^{3} / \mu 1$, with a short life of 7-10 days $(1,2)$. The platelet is an essential blood component that modulates vascular system integrity through coagulation mechanisms, but is also implicated in inflammation and cancer $(3,4)$. Resting platelets are $\sim 3 \mu \mathrm{m}$ in diameter whilst circulating inside blood vessels (5), and are activated upon contact with the surface of non-vascular intima, such as a surface injury accompanied by exposure of collagen and other agonists (6). The activated platelets then stimulate platelet glycoproteins and release molecules in order to enhance hemostasis (7).

A variety of circumstances, including cancer therapy, trauma, immune disorders, sepsis and inherited platelet defects, may result in thrombocytopenia $(8,9)$. Platelet transfusion efficiently protects patients with severe thrombocytopenia from potentially life-threatening hemorrhage (8). In addition, due to the aging of the population, and the increase in the rate of bone marrow (BM) transplantation (10-12), the demand for platelet transfusion is constantly rising. However, platelet availability is solely donor-dependent at present. The short life of 5 days (13), harsh preservation conditions and high risk of bacterial growth contribute toward the relatively limited supply for clinical use $(14,15)$. Therefore, an increasing number of studies focus on investigating factors that induce megakaryocyte (MK) differentiation and producing platelets from stem cells for clinical application $(16,17)$. With the continuing research, various genetic factors regulating megakaryocytopoiesis and platelet generation are becoming increasingly elucidated and initial success has been reported $(13,18)$.

In addition to the urgent demand of platelets for clinical use, there is a serious problem among patients who require repeated transfusions, as they often develop platelet transfusion refractoriness (PTR) associated with alloimmunization (19). These patients not only face a marked increase in the costs of healthcare, but also have higher morbidity and mortality rates (20). Furthermore, adverse events may occur in transfusion recipients. Ex vivo generation of platelets in the laboratory (21) may solve this problem. The findings of recent studies may enable platelet production on a large scale 
under specific conditions (22-24). However, the clinical supply remains high.

Achieving highly efficient production of platelets ex vivo in the $\mathrm{BM}$ is a challenging task. A more detailed understanding of the process from platelet formation to release is urgently required. On this basis, the present review is focused on platelet development from stem cells.

\section{Stem cell sources}

Various types of stem cell may produce platelets, each with specific advantages and disadvantages in terms of scalability, platelet function and other aspects (25). Therefore, these must be taken into consideration during platelet production. Hematopoietic stem cells (HSCs) are a well-known traditional stem cell source. However, they are not widely used due to their limited numbers. It has been demonstrated that induced pluripotent stem cells (iPSCs), human embryonic stem cells (hESCs) and other stem cell sources, may overcome the shortcomings of HSCs (26), thereby providing a novel approach to large-scale platelet production (Table I). All these types of cell are briefly described in the present review.

HSCs. HSCs, also known as $\mathrm{CD}^{+} 4^{+}$cells, are the simplest stem cell source for generating platelets. At present, HSCs are mainly obtained from the BM, umbilical cord blood (UCB) and peripheral blood $(27,28)$.

UCB-derived HSCs typically have a higher ability to proliferate compared with the other two types of cells (29). However, a previous study demonstrated that UCB-derived $\mathrm{CD} 34^{+}$cells were difficult to mature fully, with $<10 \% \mathrm{MKs}$ induced from UCB identified as polyploid after one week of thrombopoietin (TPO) induction (30). Current UCB availability is also limited.

Compared with BM and UCB, peripheral blood is easier to obtain and the procedure is less invasive. An increasing number of studies preferentially use peripheral blood as a source of HSCs $(31,32)$. Following procurement, HSCs may be isolated and further cultured into MKs. However, the main problem with peripheral blood is that HSCs are rare $(<0.1 \%$ of all nucleated cells in the circulation), resulting in an insufficient yield of MKs (33-35). In addition, cell culture is very slow and labor-intensive for large-scale production (36).

iPSCs. iPSCs are created by artificially inducing non-pluripotent cells to express specific genes (37). Due to the limited availability of HSCs, further studies on iPSCs have been undertaken. Over the past years, iPSCs have shown great potential in biomedical research $(38,39)$.

Feng et al (40) created a three-step protocol to generate MKs and functional platelets from iPSCs in a scalable manner within 20 days. In addition, the MK progenitors produced with their method may be stored at low temperatures and proliferate rapidly within a short time. Further analyses demonstrated that iPSC-derived platelets exhibited no major differences with platelets in the circulation. Subsequently, iPSC-derived platelets without major histocompatibility antigen (HLA) were successfully generated by knocking out the $\beta 2$-microglobulin gene (40). Another study generated a stable HLA-universal iPSC line by silencing the expression of HLA class I up to
$82 \%$ successfully (41). This HLA-universal iPSC line was able to renew MKs and functional platelets with low immunogenicity. More importantly, iPSC-derived HLA-universal MKs had the ability to escape antibody-dependent cell-mediated cytotoxicity and produce platelets for transfusion. Once the HLA-universal MKs and platelets are efficiently generated, the problem of PTR and limited platelet supply may be resolved.

hESCs. hESCs are primitive pluripotent stem cells derived from a human blastocyst inner cell mass. They can be propagated indefinitely in vitro, providing an ideal unlimited source for large-scale production of platelets (2). Several methods for differentiating hESCs into MKs have been developed over time (42). Gaur et al (42) demonstrated that hESC-derived $\mathrm{CD} 41^{+} / \mathrm{CD} 42^{+}$MKs expressed von Willebrand factor and released functional platelets, but the final number of platelets was small. Subsequently, different culture approaches were described to improve the platelet yield. Lu et al (2) achieved $60 \mathrm{MKs}$ per starting hESC with a feeder-free hESC culture approach. These hESC-derived platelets were demonstrated to have the same characteristics of platelets in the blood. Recently, the TPO gene was inserted into the adeno-associated virus integration site 1 locus of the hESC genome (43), creating cell lines stably expressing and secreting TPO. As a result, the production of hESC-derived platelets was increased, and the function of these platelets was comparable with that in the peripheral blood.

Adipose tissue-derived stromal cells (ASCs). With further studies, more strategies for producing platelets have been designed for clinical use (13). ASCs represent an attractive choice for platelet production in vitro. As ASCs contain certain essential genes indispensable for MK differentiation and platelet production, they can differentiate without gene transfer (44). Furthermore, ASCs may secrete endogenous TPO that promotes platelet production (45). Tozawa et al (46) reported a manufacturing system for platelets from the ASC line (ASCL). In the aforementioned study, ASCs were cultured in MK lineage induction media. At day 8 of culture, the maximum number of ASCL-derived MKs was achieved, and ASCL-derived platelets were obtained, with a peak at day 12 of culture. The inspection results of platelet-related functions are satisfactory.

\section{Gene regulation during megakaryopoiesis}

MKs are considered to be the progenitors of platelets (47). Multiple extrinsic and intrinsic signaling pathways are involved in megakaryopoiesis, but this process is ultimately under the control of transcription factors (48), including GATA binding protein 1 (GATA-1), friend of GATA-1 (FOG-1), friend leukemia virus integration 1 (FLI1) and runt-related transcription factor 1 (RUNX1).

GATA-1 has been reported to be a key factor during MK differentiation and maturation. GATA-1 can recruit different co-regulators to chromatin in order to participate in the process of megakaryopoiesis (49). Orkin et al (50) observed that MKs with GATA-1 knockout required a longer time to mature and exhibited marked hyperproliferation; platelet yield was lower compared with normal platelets in vivo as well. 


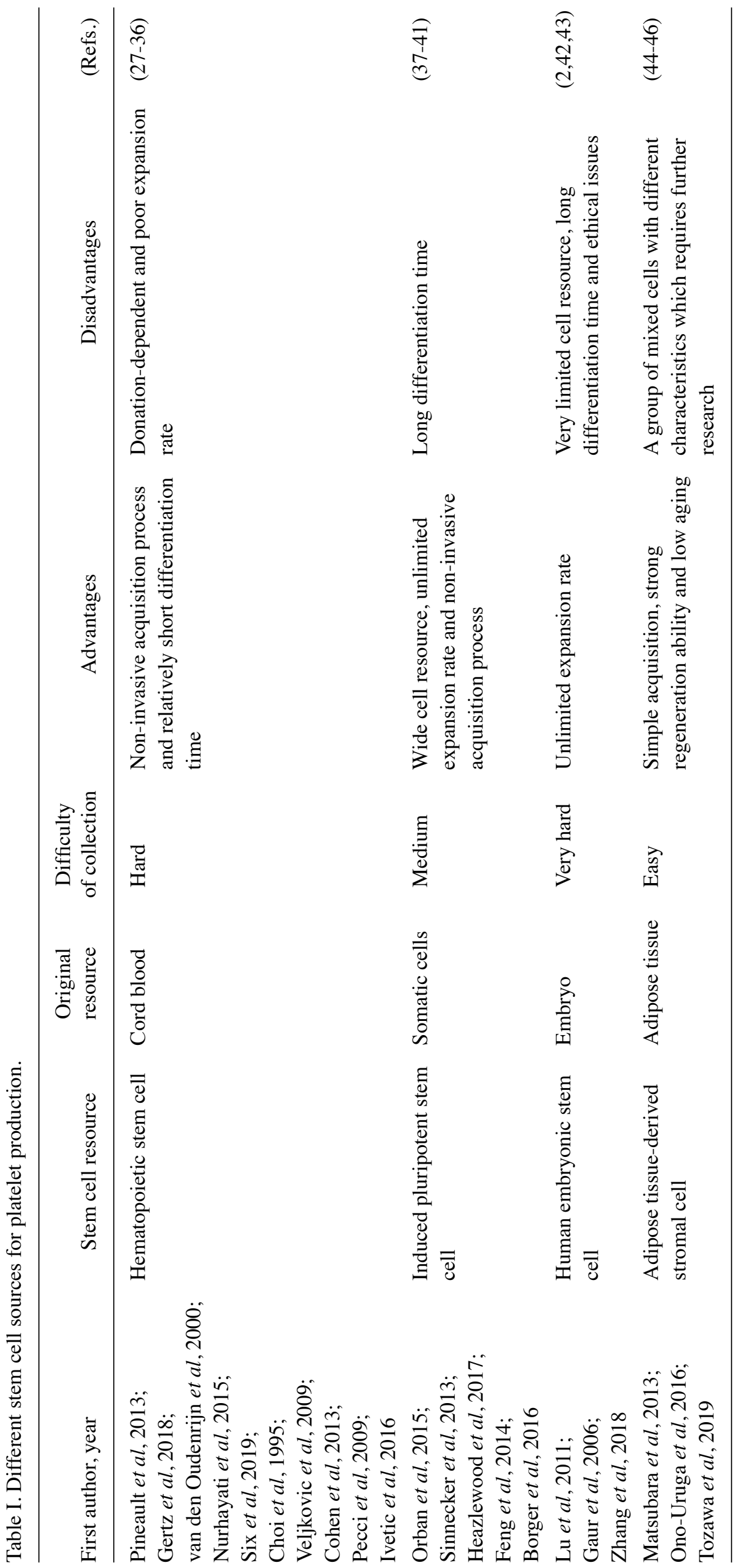


FOG-1 is a multitype zinc finger protein that can interact with GATA-1 (51). According to specific cell and promoter context, FOG-1 can enhance or inhibit the activity of GATA-1, which is important during MK differentiation $(52,53)$.

FLI1 is an E26 transformation-specific proto-oncogene domain transcription factor. Several studies have demonstrated that FLI1 serves an important role in megakaryopoiesis (54-56) and is a key regulator of megakaryopoiesis, working together with GATA-1 (57). Recently, a study investigating the effect of FLI1 during megakaryopoiesis and platelet biology further elucidated this process (58). iPSCs obtained from a patient with Paris-Trousseau syndrome and a control line with FLI1-knockout were cultured. The results revealed that platelets production was decreased in the two cell lines. Overexpression of FLI1 was shown to increase the yield and functionality of platelets (58).

The transcription factor RUNX1 is pivotal in MK development. For example, Okada et al (59) demonstrated that the depletion of RUNX1 in UT-7/GM cells led to overexpression of MK markers; however, cell proliferation was decreased at the same time.

The Tribbles Pseudokinase 3 gene (TRIB3) encodes a pleiotropic protein (60) and further study revealed that it is involved in the regulation of cell differentiation. Butcher et al (61) built a cellular model system of hematopoietic lineage differentiation in vitro. Results from this model demonstrated that TRIB3 acted as a negative modulator during megakaryopoiesis. In primary hematopoietic cell culture, TRIB3-silencing enhanced MK differentiation. By contrast, overexpression of TRIB3 decreased MK differentiation (61).

C3G, also referred to RAPGEF1, is an activator of Rap1 GTPases. It is involved in platelet activation and several other important biological processes $(62,63)$. Ortiz-Rivero et al $(64)$ evaluated $\mathrm{C} 3 \mathrm{G}$ function in megakaryopoiesis using a transgenic mouse model. The results indicated that BM cells from transgenic C3G mice exhibited increased CD41 and CD61 expression. Overexpression of $\mathrm{C} 3 \mathrm{G}$ also increased the number of CD $41^{+}$MKs. Subsequently, three different cell lines were cultured, including K562, human erythroleukemia cell line and DAMI, with overexpression or silencing of C3G or GATA-1. It was observed that GATA-1 promoted C3G expression during MK differentiation (64).

\section{Promotion of platelet production}

Platelet production takes place under specific conditions in the BM microenvironment, with various chemokines, growth factors, calcium, oxygen and adhesive interactions regulating megakaryocytopoiesis and MK migration (48). Several advances have been made to date in the study of promoting platelet production.

Microenvironment of platelet production. The dimensions, hardness, matrix components and other conditions of the BM microenvironment accurately mediate the effects of environmental factors on platelet production. A variety of associated studies have improved our understanding of this process (65-68).

A three-dimensional environment expands the contact area of MKs with the surrounding environment. Platelet production may be promoted through the interaction of proplatelets with the microenvironment $(65,66)$.

Transient receptor potential cation channel subfamily $\mathrm{V}$ member 4 , sensitive to ion channels, can trigger calcium influx, $\beta 1$ integrin activation and internalization, and human Akt phosphorylation in order to promote platelet production (67); this process only occurs when MKs adhere to a softer instead of a harder matrix. Experiments demonstrated that lysyl oxidase (LOX) may modulate the stiffness of the BM matrix via collagen crosslinking (68). Therefore, appropriate conditions, including increased LOX levels and a softer matrix, favor platelet production. Prior to blood cell release in the circulation, the interaction between progenitor cells and the vasculature is crucial (68). In order to simulate the vascular network, a custom perfusion chamber containing a multi-channel lyophilized silk sponge was constructed (68), which increased platelet production efficiently.

Previous studies observed in vivo flow dynamics and have conducted a series of experiments $(24,69)$. It was reported that turbulent flow was a crucial physical factor for platelet release (24). Based on this result, a novel bioreactor with a flow chamber and multiple pillars was developed, and further experiments produced a higher number of platelets (69).

Different induction factors of platelet production. The factors most widely used to promote platelet production include interleukin-3 (IL-3), IL-6, IL-9, IL-11 and TPO (70-72).

IL-3, IL-6, IL-9 and IL-11 affect TPO-induced MK production indirectly (70-72). Experiments in vitro indicated that the addition of mixed cytokines mentioned above could stimulate platelet production (73-75). IL-3 and TPO act synergistically in promoting $\mathrm{MK}$ differentiation (73). In the inflammatory state, IL-6 promotes proplatelet formation by increasing the level of TPO (74). Stem cell factor also plays an important role in promoting cell proliferation in the early stage of MK differentiation (73).

TPO is a major regulator of platelet production and is mainly produced by liver cells in serum (75). TPO combines with Mpl to regulate the differentiation, development, maintenance and proliferation of HSCs and MKs (75). The level of free TPO in the plasma increases when the platelet count decreases, stimulating hematopoietic progenitor cells in the BM to differentiate into MK lines to produce more platelets (76).

Eltrombopag (EP) is a second-generation TPO receptor (TPO-R) agonist that promotes the differentiation and proliferation of MKs and platelet generation. It is combined with the c-Mpl transmembrane area of the TPO-R of MKs, leading to the activation of Janus kinase 2 and tyrosine kinase 2, and phosphorylation of related signaling pathways. All these processes induce proliferation and differentiation of MKs and platelet generation $(77,78)$. All these processes induce proliferation and differentiation of MKs, as well as platelet generation (77). EP was first approved by the Food and Drug Administration for clinical use in 2008. Reported results to date have indicated that thrombocytopenia caused by chronic immune thrombocytopenic purpura (78), severe aplastic anemia (79) and chronic infection with the hepatitis $C$ virus (80) notably improved following administration of EP. 
Romiplostim is a synthetic polypeptide that activates downstream signals and stimulates platelet production by binding to the TPO-R on MKs (81). A multicenter study of romiplostim for chemotherapy-induced thrombocytopenia was conducted in solid tumors and hematological malignancies; the results demonstrated that $71 \%$ of patients responded to romiplostim and weekly dosing was found to be superior to intracycle dosing (82). An analysis of five clinical trials proved that romiplostim self-administration could achieve $95 \%$ response without adverse effects (83). Hosokawa et al (84) found that high-dose romiplostim was highly effective in patients with AA who were refractory to EP. Furthermore, sequential therapy with EP followed by romiplostim may further improve the prognosis of patients with AA who are refractory to conventional therapy (84).

\section{Conclusions}

Significant advances have been made in terms of platelet production from stem cells, and this field is progressing steadily. Different stem cell sources display specific characteristics so that the most appropriate source may be selected based on various requirements. Associated studies on gene regulations, production microenvironment conditions and inducing factors may aid in providing more insight. Further progress must be made in platelet production in order to meet the clinical requirements. More accessible stem cell sources, large-scale platelet production in vitro, more effective inducing factors and various other problems remain unresolved. However, despite these challenges, the continuous breakthroughs and developments may overcome these obstacles and achieve the final goal, which will hopefully prolong the life span of more patients in need of platelet transfusion.

\section{Acknowledgements}

Not applicable.

\section{Funding}

The present study was supported by the Natural Science Foundation of Jiangsu Province for Youth (grant no. BK20180372), Jiangsu Provincial Medical Youth Talent (grant no. QNRC2016812) and Key Medical of Jiangsu Province (grant no. ZDXKB2016020).

\section{Availability of data and materials}

Not applicable.

\section{Authors' contributions}

JY was a major contributor in writing the manuscript. JL revised the manuscript. YS was involved in writing the manuscript. BC designed the study. All authors read and approved the final manuscript.

\section{Ethics approval and consent to participate}

Not applicable.

\section{Patient consent for publication}

Not applicable.

\section{Competing interests}

The authors declare that they have no competing interests.

\section{References}

1. Wang B and Zheng J: Platelet generation in vivo and in vitro. Springerplus 5: 787, 2016.

2. Lu SJ, Li F, Yin H, Feng Q, Kimbrel EA, Hahm E, Thon JN, Wang W, Italiano JE, Cho J and Lanza R: Platelets generated from human embryonic stem cells are functional in vitro and in the microcirculation of living mice. Cell Res 21: 530-545, 2011.

3. Golebiewska EM and Poole AW: Platelet secretion: From haemostasis to wound healing and beyond. Blood Rev 29: 153-162, 2015

4. Franco AT, Corken A and Ware J: Platelets at the interface of thrombosis, inflammation, and cancer. Blood 126: 582-588, 2015.

5. Nachmias VT and Yoshida KI: The cytoskeleton of the blood platelet: A Dynamic Structure. Advances Mol Cell Biol 2: 181-211, 1988.

6. Nurhayati RW, Ojima Y and Taya M: Recent developments in ex vivo platelet production. Cytotechnology 68: 2211-2221, 2016.

7. Saluk J, Bijak M, Ponczek MB and Wachowicz B: The formation, metabolism and the evolution of blood platelets. Postepy Hig Med Dosw (Online) 68: 384-391, 2014 (In Polish).

8. Sim X, Poncz M, Gadue P and French DL: Understanding platelet generation from megakaryocytes: Implications for in vitro-derived platelets. Blood 127: 1227-1233, 2016.

9. Stasi R: How to approach thrombocytopenia. Hematology Am Soc Hematol Educ Program 2012: 191-197, 2012.

10. Gollomp K, Lambert MP and Poncz M: Current status of blood 'pharming': Megakaryoctye transfusions as a source of platelets. Curr Opin Hematol 24: 565-571, 2017.

11. Ellingson KD, Sapiano MRP, Haass KA, Savinkina AA, Baker ML, Chung KW, Henry RA, Berger JJ, Kuehnert MJ and Basavaraju SV: Continued decline in blood collection and transfusion in the United States-2015. Transfusion 57 (Suppl 2): S1588-S1598, 2017.

12. Estcourt LJ: Why has demand for platelet components increased? A review. Transfus Med 24: 260-268, 2014.

13. Baigger A, Blasczyk R and Figueiredo C: Towards the manufacture of megakaryocytes and platelets for clinical application. Transfus Med Hemother 44: 165-173, 2017.

14. Whitaker B, Rajbhandary S, Kleinman S, Harris A and Kamani N: Trends in United States blood collection and transfusion: Results from the 2013 AABB Blood Collection, Utilization, and patient blood management survey. Transfusion 56: 2173-2183, 2016.

15. Thon JN, Medvetz DA, Karlsson SM and Italiano JE Jr: Road blocks in making platelets for transfusion. J Thromb Haemost 13 (Suppl 1): S55-S62, 2015.

16. Reems JA, Pineault N and Sun S: In vitro megakaryocyte production and platelet biogenesis: state of the art. Transfus Med Rev 24: 33-43, 2010.

17. Lambert MP, Sullivan SK, Fuentes R, French DL and Poncz M: Challenges and promises for the development of donor-independent platelet transfusions. Blood 121: 3319-3324, 2013.

18. Fujiyama S, Hori N, Sato T, Enosawa S, Murata M and Kobayashi E: Development of an ex vivo xenogeneic bone environment producing human platelet-like cells. PLoS One 15: e0230507, 2020.

19. Brand A: Alloimmune platelet refractoriness: Incidence declines, unsolved problems persist. Transfusion 41: 724-726, 2001.

20. Avanzi MP and Mitchell WB: Ex vivo production of platelets from stem cells. Br J Haematol 165: 237-247, 2014.

21. Sugimoto $\mathrm{N}$ and Eto K: Platelet production from induced pluripotent stem cells. J Thromb Haemost 15: 1717-1727, 2017.

22. Nakamura-Ishizu A, Matsumura T, Stumpf PS, Umemoto T, Takizawa H, Takihara Y, O'Neil A, Majeed Abba, MacArthur BD and Suda T: Thrombopoietin metabolically primes hematopoietic stem cells to megakaryocyte-lineage differentiation. Cell Rep 25: 1772-1785 e6, 2018.

23. Chen $\mathrm{Z}$, Wang $\mathrm{Z}$ and $\mathrm{Gu} \mathrm{Z}$ : Bioinspired and biomimetic nanomedicines. Acc Chem Res 52: 1255-1264, 2019. 
24. Morishima N and Nakanishi K: Proplatelet formation in megakaryocytes is associated with endoplasmic reticulum stress Genes Cells 21: 798-806, 2016.

25. Borst S, Sim X, Poncz M, French DL and Gadue P: Induced pluripotent stem cell-derived megakaryocytes and platelets for disease modeling and future clinical applications. Arterioscler Thromb Vasc Biol 37: 2007-2013, 2017.

26. Smith BW and Murphy GJ: Stem cells, megakaryocytes, and platelets. Curr Opin Hematol 21: 430-437, 2014.

27. Pineault N, Robert A, Cortin V and Boyer L: Ex vivo differentiation of cord blood stem cells into megakaryocytes and platelets. Methods Mol Biol 946: 205-224, 2013.

28. Gertz JM, McLean KC and Bouchard BA: Endocytosed factor $\mathrm{V}$ is trafficked to $\mathrm{CD} 42 \mathrm{~b}^{+}$proplatelet extensions during differentiation of human umbilical cord blood-derived megakaryocytes. J Cell Physiol 233: 8691-8700, 2018.

29. van den Oudenrijn S, von dem Borne AE and de Haas M: Differences in megakaryocyte expansion potential between CD34 ${ }^{+}$stem cells derived from cord blood, peripheral blood, and bone marrow from adults and children. Exp Hematol 28: 1054-1061, 2000.

30. Nurhayati RW, Ojima Y and Taya M: BMS-777607 promotes megakaryocytic differentiation and induces polyploidization in the CHRF-288-11 cells. Hum Cell 28: 65-72, 2015.

31. Six KR, Sicot G, Devloo R, Feys HB, Baruch D and Compernolle V: A comparison of haematopoietic stem cells from umbilical cord blood and peripheral blood for platelet production in a microfluidic device. Vox Sang 114: 330-339, 2019.

32. Choi ES, Nichol JL, Hokom MM, Hornkohl AC and Hunt P Platelets generated in vitro from proplatelet-displaying human megakaryocytes are functional. Blood 85: 402-413, 1995.

33. Veljkovic DK, Rivard GE, Diamandis M, Blavignac J, Cramer-Borde EM and Hayward CP: Increased expression of urokinase plasminogen activator in Quebec platelet disorder is linked to megakaryocyte differentiation. Blood 113: 1535-1542, 2009.

34. Cohen KS, Cheng S, Larson MG, Cupples LA, McCabe EL, Wang YA, Ngwa JS, Martin RP, Klein RJ, Hashmi B, et al: Circulating CD34(+) progenitor cell frequency is associated with clinical and genetic factors. Blood 121: e50-e56, 2013.

35. Pecci A, Malara A, Badalucco S, Bozzi V, Torti M, Balduini CL and Balduini A: Megakaryocytes of patients with MYH9-related thrombocytopenia present an altered proplatelet formation. Thromb Haemost 102: 90-96, 2009.

36. Ivetic N, Nazi I, Karim N, Clare R, Smith JW, Moore JC, Hope KJ, Kelton JG and Arnold DM: Producing megakaryocytes from a human peripheral blood source. Transfusion 56 1066-1074, 2016

37. Orban M, Goedel A, Haas J, Sandrock-Lang K, Gartner F, Jung CB, Zieger B, Parrotta E, Kurnik K, Sinnecker D, et al: Functional comparison of induced pluripotent stem cell- and blood-derived GPIIbIIIa deficient platelets. PLoS One 10 e0115978, 2015.

38. Sinnecker D, Goedel A, Laugwitz KL and Moretti A: Induced pluripotent stem cell-derived cardiomyocytes: A versatile tool for arrhythmia research. Circ Res 112: 961-968, 2013

39. Heazlewood SY, Nilsson SK, Cartledge K, Be CL, Vinson A, Gel M and Haylock DN: Progress in bio-manufacture of platelets for transfusion. Platelets 28: 649-656, 2017.

40. Feng Q, Shabrani N, Thon JN, Huo H, Thiel A, Machlus KR, Kim K, Brooks J, Li F, Luo C, et al: Scalable generation of universal platelets from human induced pluripotent stem cells. Stem Cell Reports 3: 817-831, 2014.

41. Börger AK, Eicke D, Wolf C, Gras C, Aufderbeck S, Schulze K, Engels L, Eiz-Vesper B, Schambach A, Guzman CA, et al: Generation of HLA-Universal iPSC-derived megakaryocytes and platelets for survival under refractoriness conditions. Mol Med 22: 274-285, 2016

42. Gaur M, Kamata T, Wang S, Moran B, Shattil SJ and Leavitt AD: Megakaryocytes derived from human embryonic stem cells: A genetically tractable system to study megakaryocytopoiesis and integrin function. J Thromb Haemost 4 436-442, 2006

43. Zhang L, Liu C, Wang H, Wu D, Su P, Wang M, Guo J, Zhao S, Dong $\mathrm{S}$, Zhou W, et al: Thrombopoietin knock-in augments platelet generation from human embryonic stem cells. Stem Cell Res Ther 9: 194, 2018.

44. Matsubara Y, Ono Y, Suzuki H, Arai F, Suda T, Murata M and Ikeda Y: OP9 bone marrow stroma cells differentiate into megakaryocytes and platelets. PLoS One 8: e58123, 2013.
45. Ono-Uruga Y, Tozawa K, Horiuchi T, Murata M, Okamoto S, Ikeda Y, Suda T and Matsubara Y: Human adipose tissue-derived stromal cells can differentiate into megakaryocytes and platelets by secreting endogenous thrombopoietin. J Thromb Haemost 14: 1285-1297, 2016

46. Tozawa K, Ono-Uruga Y, Yazawa M, Mori T, Murata M, Okamoto S, Ikeda Y and Matsubara Y: Megakaryocytes and platelets from a novel human adipose tissue-derived mesenchymal stem cell line. Blood 133: 633-643, 2019.

47. McArthur K, Chappaz S and Kile BT: Apoptosis in megakaryocytes and platelets: The life and death of a lineage. Blood 131: 605-610, 2018.

48. Guo T, Wang $\mathrm{X}, \mathrm{Qu} \mathrm{Y}$, Yin $\mathrm{Y}$, Jing $\mathrm{T}$ and Zhang $\mathrm{Q}$ Megakaryopoiesis and platelet production: Insight into hematopoietic stem cell proliferation and differentiation. Stem Cell Investig 2: 3, 2015.

49. Pope NJ and Bresnick EH: Differential coregulator requirements for function of the hematopoietic transcription factor GATA-1 at endogenous loci. Nucleic Acids Res 38: 2190-2200, 2010.

50. Orkin SH, Shivdasani RA, Fujiwara Y and McDevitt MA: Transcription factor GATA-1 in megakaryocyte development. Stem Cells 16 (Suppl 2): S79-S83, 1998.

51. Wang X, Crispino JD, Letting DL, Nakazawa M, Poncz M and Blobel GA: Control of megakaryocyte-specific gene expression by GATA-1 and FOG-1: Role of Ets transcription factors. EMBO J 21: 5525-5234, 2002

52. Gao Z, Huang Z, Olivey HE, Gurbuxani S, Crispino JD and Svensson EC: FOG-1-mediated recruitment of NuRD is required for cell lineage re-enforcement during haematopoiesis. EMBO J 29: 457-468, 2010.

53. Lejon S, Thong SY, Murthy A, AlQarni S, Murzina NV, Blobel GA, Laue ED and Mackay JP: Insights into association of the NuRD complex with FOG-1 from the crystal structure of an RbAp48.FOG-1 complex. J Biol Chem 286: 1196-1203, 2011.

54. Hart A, Melet F, Grossfeld P, Chien K, Jones C, Tunnacliffe A, Favier R and Bernstein A: Fli-1 is required for murine vascular and megakaryocytic development and is hemizygously deleted in patients with thrombocytopenia. Immunity 13: 167-177, 2000.

55. Starck J, Weiss-Gayet M, Gonnet C, Guyot B, Vicat JM and Morle F: Inducible Fli-1 gene deletion in adult mice modifies several myeloid lineage commitment decisions and accelerates proliferation arrest and terminal erythrocytic differentiation. Blood 116: 4795-4805, 2010.

56. Deutsch VR and Tomer A: Advances in megakaryocytopoiesis and thrombopoiesis: From bench to bedside. Br J Haematol 161: 778-793, 2013.

57. Eisbacher M, Holmes ML, Newton A, Hogg PJ, Khachigian LM, Crossley $\mathrm{M}$ and Chong $\mathrm{BH}$ : Protein-protein interaction between Fli-1 and GATA-1 mediates synergistic expression of megakaryocyte-specific genes through cooperative DNA binding. Mol Cell Biol 23: 3427-3441, 2003.

58. Vo KK, Jarocha DJ, Lyde RB, Hayes V, Thom CS, Sullivan SK, French DL and Poncz M: FLI1 level during megakaryopoiesis affects thrombopoiesis and platelet biology. Blood 129: 3486-3494, 2017

59. Okada Y, Nagai R, Matsuura E, Hoshika Y, Nakata E, Nagura H, Watanabe A, Komatsu N and Doi T: Suppression of RUNX1 by siRNA in megakaryocytic UT-7/GM cells. Nucleic Acids Symp Ser (Oxf): 261-262, 2006

60. Mata J, Curado S, Ephrussi A and Rørth P: Tribbles coordinates mitosis and morphogenesis in Drosophila by regulating string/CDC25 proteolysis. Cell 101: 511-522, 2000.

61. Butcher L, Ahluwalia M, Ord T, Johnston J, Morris RH, Kiss-Toth E, Ord T and Erusalimsky JD: Evidence for a role of TRIB3 in the regulation of megakaryocytopoiesis. Sci Rep 7: 6684,2017

62. Gotoh A, Miyazawa K, Ohyashiki K, Tauchi T, Boswell HS, Broxmeyer HE and Toyama K: Tyrosine phosphorylation and activation of focal adhesion kinase (p125FAK) by BCR-ABL oncoprotein. Exp Hematol 23: 1153-1159, 1995.

63. Gotoh T, Niino Y, Tokuda M, Hatase O, Nakamura S, Matsuda M and Hattori S: Activation of R-Ras by Ras-guanine nucleotide-releasing factor. J Biol Chem 272: 18602-18607, 1997.

64. Ortiz-Rivero S, Baquero C, Hernandez-Cano L, Roldan-Etcheverry JJ, Gutierrez-Herrero S, Fernandez-Infante C, Martin-Granado V, Anguita E, de Pereda JM, Porras A and Guerrero C: C3G, through its GEF activity, induces megakaryocytic differentiation and proplatelet formation. Cell Commun Signal 16: 101, 2018 
65. Sullenbarger B, Bahng JH, Gruner R, Kotov N and Lasky LC: Prolonged continuous in vitro human platelet production using three-dimensional scaffolds. Exp Hematol 37: 101-110, 2009.

66. Malara A,Currao M, GruppiC,CelestiG, Viarengo G, BuracchiC, Laghi L, Kaplan DL and Balduini A: Megakaryocytes contribute to the bone marrow-matrix environment by expressing fibronectin, type IV collagen, and laminin. Stem Cells 32: 926-937, 2014.

67. Abbonante V, Di Buduo CA, Gruppi C, De Maria C, Spedden E, De Acutis A, Staii C, Raspanti M, Vozzi G, Kaplan DL, et al A new path to platelet production through matrix sensing. Haematologica 102: 1150-1160, 2017.

68. Tozzi L, Laurent PA, Di Buduo CA, Mu X, Massaro A, Bretherton R, Stoppel W, Kaplan DL and Balduini A: Multi-channel silk sponge mimicking bone marrow vascular niche for platelet production. Biomaterials 178: 122-133, 2018.

69. Ito Y, Nakamura S, Sugimoto N, Shigemori T, Kato Y, Ohno M, Sakuma S, Ito K, Kumon H, Hirose H, et al: Turbulence activates platelet biogenesis to enable clinical scale ex vivo production. Cell 174: 636-648 e18, 2018.

70. Jiang HJ, Yu Z, Ding N, Yang M, Zhang L, Fan XM, Zhou Y, Zou Q, Hou J, Zheng J, et al: The role of AGK in thrombocytopoiesis and possible therapeutic strategies. Blood 136: 119-129, 2020.

71. Kaushansky K, Broudy VC, Lin N, Jorgensen MJ, McCarty J, Fox N, Zucker-Franklin D and Lofton-Day C: Thrombopoietin, the Mp1 ligand, is essential for full megakaryocyte development. Proc Natl Acad Sci USA 92: 3234-3238, 1995.

72. Panuganti S, Schlinker AC, Lindholm PF, Papoutsakis ET and Miller WM: Three-stage ex vivo expansion of high-ploidy megakaryocytic cells: Toward large-scale platelet production. Tissue Eng Part A 19: 998-1014, 2013.

73. Chang Y, Bluteau D, Debili N and Vainchenker W: From hematopoietic stem cells to platelets. J Thromb Haemost 5 (Suppl 1): S318-S327, 2007.

74. Behrens K and Alexander WS: Cytokine control of megakaryopoiesis. Growth Factors 36: 89-103, 2018.

75. Fielder PJ, Gurney AL, Stefanich E, Marian M, Moore MW, Carver-Moore K and de Sauvage FJ: Regulation of thrombopoietin levels by c-mpl-mediated binding to platelets. Blood 87 $2154-2161,1996$.
76. He X, Chen Z, Jiang Y, Qiu X and Zhao X: Different mutations of the human c-mpl gene indicate distinct haematopoietic diseases. J Hematol Oncol 6: 11, 2013.

77. Di Buduo CA, Currao M, Pecci A, Kaplan DL, Balduini CL and Balduini A: Revealing eltrombopag's promotion of human megakaryopoiesis through AKT/ERK-dependent pathway activation. Haematologica 101: 1479-1488, 2016.

78. Wong RSM, Saleh MN, Khelif A, Salama A, Portella MSO, Burgess P and Bussel JB: Safety and efficacy of long-term treatment of chronic/persistent ITP with eltrombopag: Final results of the EXTEND study. Blood 130: 2527-2536, 2017.

79. Gill H, Leung GM, Lopes D and Kwong YL: The thrombopoietin mimetics eltrombopag and romiplostim in the treatment of refractory aplastic anaemia. Br J Haematol 176: 991-994, 2017.

80. Fischer JC and Uhrberg M: Prevention of leukemia relapse by donor activating KIR2DS1. N Engl J Med 367: 2054-2055, 2012.

81. Al-Samkari H, Grace RF and Kuter DJ: The role of romiplostim for pediatric patients with immune thrombocytopenia. Ther Adv Hematol 11: 2040620720912992, 2020.

82. Al-Samkari H, Parnes AD, Goodarzi K, Weitzman JI, Connors JM and Kuter DJ: A multicenter study of romiplostim for chemotherapy-induced thrombocytopenia in solid tumors and hematologic malignancies. Haematologica: Jun 4, 2020 (Epub ahead of print). doi.org/10.3324/haematol.2020.251900.

83. Kuter DJ, Arnold DM, Rodeghiero F, Janssens A, Selleslag D, Bird R, Newland A, Mayer J, Wang K and Olie R: Safety and efficacy of self-administered romiplostim in patients with immune thrombocytopenia: Results of an integrated database of five clinical trials. Am J Hematol 95: 643-651, 2020.

84. Hosokawa K, Yamazaki H, Tanabe M, Imi T, Sugimori N and Nakao S: High-dose romiplostim accelerates hematologic recovery in patients with aplastic anemia refractory to eltrombopag. Leukemia, Jul 3, 2020 (Epub ahead of print). doi org/10.1038/s41375-020-0950-6.

This work is licensed under a Creative Commons Attribution-NonCommercial-NoDerivatives 4.0 International (CC BY-NC-ND 4.0) License. 